\title{
Babaların Okul Öncesi Dönemdeki Çocuklarıyla İlişkisinin Bazı Değişkenlere Göre İncelenmesi*
}

\section{Examination of Relationship Between Preschool Children and Their Fathers According to Some Variables}

\author{
Halil UZUN**, Gülen BARAN***
}

\begin{abstract}
Öz: Yirminci yüzyılda, birçok araştırmacı, anne-baba tutum ve davranışlarının çocuk gelişiminde etkili olduğunu belirtmiştir. Bununla birlikte, annelerle ilgili birçok araştırmaya ek olarak, son yıllarda birçok araştırma, çocuk gelişimine etkili olduğu düşünülen babalara odaklanmıştır. Bu doğrultuda, bu araştırmada okul öncesi dönem çocukları ve babaları arasındaki ilişki düzeyinin bazı değişkenlere göre belirlenmesi amaçlanmıştır. Bu çalışmada betimsel tarama modeli kullanılmıştır. Araştırmaya, anaokulunda çocuğu olan ve Kilis ilinde yaşayan 158 baba katılmıştır. Veri toplama aracı olarak Çocuk Ebeveyn İlişki Ölçeği Baba Formu (Uzun ve Baran, 2015) kullanılmıştır. Verilerin analizinde Kruskall Wallis ve Mann Whitney U testlerinden yararlanılmıştır. İstatistiksel analiz sonucunda, babaların yaşı, çocuğun yaşı, evlilik süresi, çocuğun doğum sırası ve babanın eğitim durumu açısından gruplar arasında anlamlı farklılıklar olduğu görülmüştür. Mevcut çalışmanın bulgularına dayanarak, babanın eğitim durumundaki artışın baba ile çocuk arasındaki ilişkiyi olumlu yönde etkilediği tespit edilmiştir. Bununla birlikte, genç babaların çocuklarıyla ilişki düzeyinin, yaşlı babalardan daha olumlu olduğu bulunmuştur. Ayrıca bulgular, uzun evlilik süresinin baba çocuk arasındaki ilişkiyi olumsuz etkilediğini göstermiştir.
\end{abstract}

Anahtar kelimeler: Okul öncesi eğitim, çocuk-ebeveyn ilişkisi, ebeveynlik, baba çocuk ilişkisi

\begin{abstract}
In the twentieth century, many researchers conducted that parental attitudes and behaviors are influential in child development. However, in addition to the many researches on mothers, many researches in recent years have focused on the fathers who are thought to be influential to child development. In this research it is aimed to determine the level of relationship between the father and their preschool children according to some variables. In this study, the descriptive research model was adopted. 158 fathers who have children in kindergarden and living in the province of Kilis in Turkey were included in the survey. The Child Parent Relation Scale Father Form (Uzun ve Baran, 2015) was used. Data were analyzed through Mann Withney U and Kruskall Wallis tests. As a result of statistical analysis, It was seen that there were significant differences between groups in terms of father's age, child's age, marriage duration, child's birth order and father's educational status. However, there had not been found any significant difference with child gender, mother's working status and marriage assesment. Based on the findings of the current study it is seen that the increase in the education status of the father has a positive effect on the relationship between the father and the child. However, it has been found that the level of relationship of young fathers with their children is more positive than that of older fathers. Also, findings showed that, high marriage duration effects the relationship negatively.
\end{abstract}

Keywords: Preschool education, chil-parent relationship, parenting, father child relationship

\section{Giriş}

Çocukların sağlıklı yetişkinler olmaları, sağlıklı ilişkilerin olduğu bir aile ortamında büyümelerine bağlıdır (Erkan ve Durmuşoğlu, 2006). Aile çocuğun gelişimsel sürecindeki doğru ve yanlışlar için güçlü bir belirleyici olup, çocuğun gelişimini ve öğrenmesini derinden

\footnotetext{
* Bu çalışma, 23-26 Ağustos 2017 tarihinde düzenlenen, XIV.European Conference on Social and Behavioral Sciences sempozyumunda sunulan Examination of relationship between pre-school children and their fathers according to some variables başlıklı sözlü bildirinin genişletilmiş halidir.

** Dr. Öğr. Üyesi, Kilis 7 Aralık Üniversitesi, Muallim Rıfat Eğitim Fakültesi, Kilis-Türkiye, ORCID: 0000-00030029-1074, e-posta: uzunhalil@gmail.com.

*** Prof. Dr., Ankara Üniversitesi, Sağlık Bilimleri Fakültesi, Ankara-Türkiye, ORCID: 0000-0002-5854-4946, eposta: barangln@gmail.com
} 
etkilemektedir (Morrison, 2006). Gordon'a (2009) göre, ebeveynlerin çocuk üzerindeki etkisi çok geniştir. Çocuklar birçok beceriyi ebeveynlerini gözlemleyerek ve onlardan yardım ve destek alarak öğrenirler. Bir bakıma, anne ve babalar sıfır altı yaş döneminde hem çocukların tüm ihtiyaçlarının karşılanmasında en yakınında olan kişiler, hem de ilk öğretmenleridirler. Kişiliğin gelişimsel temellerinin sıfır altı yaş döneminde atıldığı göz önüne alındığında, eğitsel kimliğin belirlenmesinde ebeveynlerin rollerinin önemi daha da iyi anlaşılmış olur. Çocuğun aile içerisinde edindiği statü, değer ve geliştirdiği kimlik, onun gelecekte toplum içerisinde kazanacağ 1 kimliğin, statünün ve değerin belirleyicisi olmaktadır. Aile çocukların gelecek yaşantısını önemli ölçüde etkilediğinden, anne babaların çocuk gelişimi ve eğitimi konusunda eğitilmeleri, çocukların daha iyi yetişmelerinde önemli rol oynamaktadır (Kaya, 2002). Anne baba eğitim programları sayesinde, çocukta daha yüksek kalitede öğrenme sağlanabilmektedir (Morrison, 2006). Günümüzde ailelerin eğitim sürecine dahil edilmediği bir eğitim ile istenen amaca ulaşmanın çok zor olduğu bilinmektedir. Bu nedenle son yıllarda aile eğitimine verilen önem gittikçe artmaktadır (Can-Toprakç1, 2006; Diler-Sönmez, 2008; Varol, 2005; Yılmaz-Bolat ve diğerleri, 2016).

Aile eğitimi, anne babayı ve çocuğa bakan kişiyi desteklemek için zengin uyarıcılı ev ortamını sağlamak, anne baba-çocuk iletişimini gerçekleştirmek, çocuğun doğumundan ilkokulun başlangıcına kadar olan devrede gelişimlerine cevap vermek amacıyla düzenlenen, anne babaların çocuklarını sağlıklı bir şekilde yetiştirmelerini sağlamayı amaçlayan etkinliklerin tümü olarak ifade dilebilir (Mahoney ve diğerleri, 1999; Wong ve diğerleri, 2006; Üstünoğlu, 1991). Bununla birlikte, aile eğitimi anne-babanın birlikte katıldı̆̆ 1 programlar olarak düzenlenebildiği gibi yalnız anne ya da yalnız babalara yönelik olarak da organize edilebilmektedir. Bu doğrultuda, özellikle son yıllarda baba eğitimine yönelik çalışmalarda artış olduğu gözlenmektedir (Çağdaş, 2008; Öz, 2005; Riley ve diğerleri, 2000; Segrin ve Flora, 2005; Tezel-Şahin, 1998). İnsan yaşamında sosyal, politik, ekonomik, kültürel ve bilimsel faktörler babanın, babalık rolünü nasıl gerçekleştireceğini önemli ölçüde belirlemektedir. Bütün bu faktörler durağan bir yapıda olmayıp değiştiğinden babalık rolünde de farklılıklar olduğu görülmektedir. Nitekim babalarla ilgili çalışmalar 1980'li yıllardan önce başlamakla birlikte, 1990'lı yıllarda bu konu uluslararası düzeyde yaygın bir biçimde konuşulup tartışılmaya başlanmıştır. Lamb'ın ortaya koyduğu Baba Katılımı Tipolojisi ile babaların çocuk gelişimi üzerindeki etkilerine yönelik çalışmalara önemli bir teorik altyapı oluşmuştur. Lamb, baba katılımının üç önemli boyutunu ortaya koymaktadır. Bunlardan birincisi, babaların çocukları ile birlikte zaman geçirmesini ifade eden etkileşimdir. İkincisi, birlikte herhangi bir etkinlik gerçekleştirilmese bile, duygusal ve fiziksel yakınlık ifade eden ve çocuğun önceliklerine zaman ayırmayı ifade eden ulaşlabilirlik, sonuncusu ise, çocuğun sağlıklı gelişimi ve mutluluğu için sorumluluk üstlenmektir (Ho ve Lamb, 1987; Koçak, 2004).

Etkileşim (Doğrudan Temas): Babanın çocuğuyla doğrudan, birebir ilişki kurduğu her türlü etkinliği kapsamaktadır. Çocukla gezmek, konuşmak, oynamak, birlikte olmak bu katılıma örnek verilebilir.

Ulaşılabilir Olma: Babanın çocuğu açısından hem bedensel, hem de psikolojik olarak ulaşılabilir olmasıdır. Babanın ulaşılabilir olması, çocuğun ihtiyaç duyduğunda babasından destek alabiliyor olması anlamına gelmektedir. Çocukların babalarını ulaşılabilir ve yanlarında hissetmeleri kendilerine güvenini olumlu etkilemektedir.

Sorumluluk: Çocuğu doktora götürmek veya arkadaşlarıyla buluşmasını organize etmek gibi çocuk adına, çocuk için bazı faaliyetleri yapmak veya yapılacakları hatırlayıp planlanmaktır. Çoğu kez anneye destek olmak anlamına da gelmektedir (Koçak, 2004). Lamb'in ortaya koyduğu model, babalar için geliştirilen birçok çalışma ve program için altyapı oluşturmuş ve son yıllarda çocuk gelişimi üzerinde baba rolü ve etkilerine ilişkin literatürde artan bir ilgiye neden olmuştur. Babalara karşı bu ilginin artmasında ve babalık rolünün değişmesinde yüksek eğitim almasıyla birlikte çalışan kadın sayısındaki artış, boşanma oranlarının yükselmesi ve geleneksel ailenin çekirdek aileye dönüşmesiyle bireye düşen rol ve sorumlulukların değişmesi vb. faktörler etkili olmuştur (Güngörmüş-Özkardeş, 2006; Heinowitz, 1998).

Günümüzde teknolojik ve ekonomik alanlardaki sürekli ve hızlı gelişme, aile yapısında ve aileyi oluşturan bireylerin görev ve sorumluluklarında da değişimlere neden olmuştur. Ekonomik şartların ağırlaşması, kadınların eğitim düzeylerinin yükselmesi ve teknolojideki 
gelişmeler her geçen gün kadın iş gücüne duyulan ihtiyacı artırmıştır. Annenin çalışma hayatına katılması ile birlikte, ailede babanın görev ve sorumluluklarında önemli değişimler olmuştur. $\mathrm{Bu}$ gelişim ve değişimlere paralel olarak baba, ailenin gelirini sağlamanın yanı sıra, çocukların bakım ve eğitimlerinde de önemli rol oynamaya başlamıştır (Çağdaş, 2008; Öz, 2005; Segrin ve Flora, 2005). Anneler çocuklarının ihtiyaçlarını karşılamak ve bakımını sağlamak gibi sorumlulukları alırken, babalar daha sıklıkla fiziksel oyunlar oynamayı tercih etmektedirler. Babalar bilişsel ve başarı ile ilgili süreçlere daha fazla katılmaktadırlar (Russel ve Russel, 1987). Baba desteğinin çocukların analiz etme becerisi, zeka düzeyi, temel beceriler, dil zekası ve akademik başarıda, sosyal ve duygusal gelişimdeki iç denetimde, olgunluk, bağımsızlık düzeyi ve psiko-sosyal uyum ile cinsel kimliğin tanımlanması ve geliştirilmesinde olumlu rol oynadı̆̆ ifade edilmektedir (Tezel-Şahin ve Özyürek, 2010). Bununla birlikte, erken çocukluk döneminde çocuklar babalarının kendilerini izlemelerinden, fikir vermelerinden, yeni şeyler öğretmelerinden, onlarla oynamaktan, kısacası babalarıyla birlikte olmaktan keyif almaktadırlar. Ayrıca bu dönemde babalarıyla birlikte olan çocuklar gelişimleri için gerekli olan birçok bilgiyi, beceriyi ve duygusal desteği elde etmektedirler. Bronstein ve Zlotnik (2008) baba çocuk ilişkisinin hem nitelik, hem de nicelik olarak anne çocuk ilişkisinden farklı olduğunu vurgulamaktadır. Araştırmacılar, babanın özellikle erkek çocuğun erkeksi davranışları kazanması açısından önemli olduğunu ortaya koymakta ve erkek çocukların babaları ile özdeşleşerek erkek gibi davranmayı öğrendiklerini ileri sürmektedirler. Bu doğrultuda baba- çocuk ilişkisinin niteliğinin çocuğun birçok alandaki gelişiminin desteklenmesi açısından önemli bir yere sahip olduğu ifade edilebilir. Bu doğrultuda, bu araştırmada okul öncesi dönem çocukları ve babaları arasındaki ilişki düzeyinin bazı değişkenlere göre belirlenmesi amaçlanmıştır.

\section{Yöntem}

\section{Araştırmanın modeli}

$\mathrm{Bu}$ araştırma, babaların okul öncesine devam eden çocuklarıyla ilişkilerini babaların görüş ve tutumlarına göre betimlemeye yönelik bir çalışmadır. Bu bağlamda araştırmada tarama modeli kullanılmıştır. Tarama modelleri, geçmişte ya da halen var olan bir durumu var olduğu şekliyle betimlemeyi amaçlayan araştırma yaklaşımlarıdır (Karasar, 2008)

\section{Çalışma grubu}

Araştırmanın örneklemini Kilis ilinde Milli Eğitim Bakanlığına bağlı resmi anaokullarına devam eden çocuğu bulunan ve araştırmaya katılmaya gönüllü 158 baba oluşturmuştur. Örneklem seçiminde random (rastgele) örnekleme yolu benimsenmiştir.

Tablo 1.

Araştırmaya Dahil Edilen Babalar ve Çocuklara İlişkin Sayısal Veriler

\begin{tabular}{|c|c|c|c|c|c|}
\hline \multirow[t]{2}{*}{ Değişkenler } & \multicolumn{3}{|r|}{ Değişkenler } & \multirow[b]{2}{*}{$\mathrm{N}$} & \multirow[b]{2}{*}{$\%$} \\
\hline & $\mathrm{N}$ & $\%$ & & & \\
\hline Çocuğun Cinsiyeti & & & Babanın Yaşı & & \\
\hline $\mathrm{K} 1 \mathrm{z}$ & 85 & 53,8 & $20-29$ yaş & 25 & 15,82 \\
\hline Erkek & 73 & 46,2 & $30-39$ yaş & 74 & 46,83 \\
\hline \multirow[t]{3}{*}{ Toplam } & 158 & 100 & $40-49$ yaş & 42 & 26,57 \\
\hline & & & 50 yaş ve üzeri & 17 & 10,78 \\
\hline & & & Toplam & 158 & 100 \\
\hline Çocuğun Doğum Sırası & & & Babanın Eğitim Durumu & & \\
\hline İlk- tek çocuk & 45 & 28,5 & İlkokul mezunu & 43 & 27,22 \\
\hline Ortancalardan biri & 78 & 49,4 & Ortaokul mezunu & 44 & 27,84 \\
\hline Son çocuk & 35 & 22,2 & Lise mezunu & 36 & 22,77 \\
\hline \multirow[t]{2}{*}{ Toplam } & 158 & 100 & Üniversite mezunu & 14 & 8,87 \\
\hline & & & Lisansüstü mezunu & 21 & 13,30 \\
\hline
\end{tabular}




\begin{tabular}{|c|c|c|c|c|c|}
\hline \multirow{2}{*}{ Çocuğun Yaş1 } & \multicolumn{3}{|r|}{ Toplam } & \multirow[t]{2}{*}{158} & \multirow[t]{2}{*}{100} \\
\hline & & & Evlilik Süresi & & \\
\hline 3-4 yaş & 74 & 46,8 & 5 yil ve daha az & 40 & 25,32 \\
\hline 4-5 yaş & 75 & 47,5 & $6-10$ y1l & 44 & 27,85 \\
\hline $5-6$ yaş & 9 & 5,7 & $11-15$ y1l & 19 & 12,02 \\
\hline \multirow[t]{3}{*}{ Toplam } & 158 & 100 & $16-20 \mathrm{y} 1 \mathrm{l}$ & 22 & 13,92 \\
\hline & & & 21 y1l ve üzeri & 33 & 20,89 \\
\hline & & & Toplam & 158 & 100 \\
\hline Babanın Çalışma Durumu & & & \multicolumn{3}{|c|}{ Babanın evliliğini nasıl değerlendirdiğgi } \\
\hline Sürekli çalışıyor & 97 & 61,4 & Oldukça uyumlu & 34 & 21,51 \\
\hline Zaman zaman çalıșıyor & 54 & 34,2 & Zaman zaman çatışmalı & 95 & 60,12 \\
\hline Çalıșmiyor & 7 & 4,4 & Uyumsuz, mutsuz & 29 & 18,37 \\
\hline Toplam & 158 & 100 & Toplam & 158 & 100 \\
\hline Annenin Çalışma Durumu & & & & & \\
\hline Sürekli çalışıyor & 43 & 27,2 & & & \\
\hline Zaman zaman çalışıyor & 58 & 36,7 & & & \\
\hline Çalışmıyor & 57 & 36,1 & & & \\
\hline Toplam & 158 & 100 & & & \\
\hline
\end{tabular}

Tablo 1'e bakıldığında, araştırmaya dahil edilen babaların çoğunun 30-39 yaş aralığında $(\% 46,83)$, büyük çoğunluğunun ilkokul $(\mathrm{n}=43, \% 27,22)$ ve ortaokul $(\mathrm{n}=44, \% 27,87)$ mezunu, 95 'inin $(\% 60,12)$ evliliklerini zaman zaman çatışmalı olarak değerlendirdiği ve \%61'inin (n=97) sürekli bir işi olduğu görülmektedir. Ayrıca çalışma grubundaki babaların çocuklarının cinsiyetlerine bakıldığında kız ve erkek sayısının birbirlerine yakın olduğu, okul öncesi kurumlara devam eden çocuklarının çoğunun ( $\mathrm{n}=78, \% 49,4)$ ortanca çocuklardan biri olduğu, en az 5-6 yaş aralığında $(\mathrm{n}=9, \% 5,7)$ çocuk olduğu ve eşlerinin 57 'sinin $(\% 36,1)$ çalışmadığ belirlenmiştir.

\section{Veri toplama}

Ölçme aracı: Araştırmada veri toplama aracı olarak Türkçe geçerlik ve güvenirliği Uzun ve Baran (2015) tarafindan gerçekleştirilen Çocuk Ebeveyn İlişkisi Öçeği-Baba Formu (ÇEİÖ-F) kullanılmıștır. Orjinali Pianta (1992) tarafindan geliștirilen (Child Parent Relationship Scale) "Çocuk Ebeveyn İlişki Ölçeği" hazırlanırken anne baba çocuk etkileşimi literatüründen, bağlanma teorisinden ve Bağlanma Q-Set ölçeğinden yararlanılmıştır. Ölçeğin hazırlanmasında veriler 4,5-5,5 yaşlarında çocukları olan 714 anne babadan elde edilmiş ve ölçek çatışma alt boyutu 14 madde, bağlanma alt boyutu 6 madde ve olumlu İlişki alt boyutu 10 madde olmak üzere toplam 30 maddeden ve üç alt boyuttan oluşmuştur. Ölçek 5'li likert tipi bir ölçek olup, (1) Kesinlikle uygun değil ile (5) Kesinlikle çok uygun arasında yanıtlanmaktadır. Bu araştırmada Pianta (1992) tarafında geliştirilen, Uzun ve Baran (2015) tarafından Türkçe'ye uyarlanan ÇEİÖB ölçeği kullanılmıştır. Geçerlik çalışması kapsamında ölçeğin dil, kapsam ve yapı geçerliği (açımlayıcı ve doğrulayıcı) çalışmaları yapılmıştır. ÇEİÖ-B Formunun güvenirlik çalışması iç güvenlik katsayısı (Cronbach alpha) ve test tekrar test güvenirliği ile gerçekleștirilmiștir. Ölçekteki maddelerin toplamı için Cronbach alpha güvenirlik katsayısı .71, olumlu ilişkiler alt boyutu için .76, uyumsuzluk alt boyutu için .61 ve çatı̧̧ma alt boyutu için .62 olarak bulunmuştur. Genellikle alfa katsayısı "0.60- $0.80 "$ arası oldukça güvenilir ve "0.80- $1.00 "$ arası yüksek derecede güvenilir olarak değerlendirmektedir. $\mathrm{Bu}$ doğrultuda bulunan değerler ölçeğin güvenirliği için yeterli sayılacak düzeydedir (Tavşanc1l, 2006). Ölçeğin zamana bağlı tutarlı ölçümler verip vermediğinin belirlenmesi amacıyla ilk uygulamadan 4 hafta sonra test-tekrar test gerçekleştirilmiştir. Elde edilen sonuçlara bakıldığında iki uygulamadan elde edilen puanların korelasyonu ölçeğin tamamı için .92, olumlu ilişkiler boyutu için .94, uyumsuzluk boyutu için .90 , çatışma boyutu için $.92(\mathrm{p}<.01)$ olarak bulunmuş ve test-tekrar test güvenirliğinin oldukça yeterli olduğu görülmüştür. Yapılan çalışmalar sonucunda ÇEİÖ-B Formunun 23 madde ve 
Olumlu ilişkiler, Uyumsuzluk ve Çatışma olmak üzere 3 alt boyuttan oluştuğu saptanmıştır. ÇEİÖ-BF'de düşük puan olumlu ilişkiyi göstermektedir. Testin her babaya uygulanma süresi ortalama 30 dakika olarak belirlenmiştir.

\section{Veri toplama işlemi}

$\mathrm{Bu}$ aşamada, okulöncesi eğitim kurumlarının idarecileri ve bu kurumlarda görev yapan öğretmenlerle görüşülerek, ölçme aracı ile ilgili gerekli bilgiler verilmiş ve ölçeği doldurmaya gönüllü babalara ölçme aracını ulaştırmaları istenmiştir. Daha sonra babalardan dönen ölçekler öğretmenlerden alınarak analiz işlemlerine başlanmıştır.

\section{Verilerin analizi}

Verilerin analizi SPSS paket programı ile yapılmıştır. Verilerin çözümlenmesinde kişisel bilgilerin değerlendirilmesinde yüzde ve frekans testlerinden yararlanılmıştır. Babaların ölçek maddelerine verdikleri cevapların analizinde ise öncelikle normallik testi yapılmış, babaların sayıs1 ( $\mathrm{n}=158)$ 50'den fazla olduğu için Kolmogorov Smirnov normallik testi uygun bulunmuştur (Büyüköztürk, 2011). Babaların ÇEİ̈- B Formu'na verdikleri cevaplardan elde edilen verilerin normal dağ 1 lım göstermediği belirlenmiştir. Bunun sonucunda verilerin analizinde nonparametrik testlerden Mann Withney U ve Kruskall Wallis testi kullanılmıştır. Kruskall Wallis testinde farklılığın hangi gruplar arasında olduğunu belirlemek için SPSS'te çoklu karşılaştırmalar (multiple comparisions) yapılmıştır.

\section{Bulgular}

$\mathrm{Bu}$ bölümde babaların çocuklarıyla ilişki düzeyine ilişkin araştırmadan elde edilen bulgular tablolar halinde sunulmuştur.

Tablo 2.

Çocukların Cinsiyetine Göre Babaların ÇEİÖ-B Formu ve Alt Boyutlarına İlişkin Mann WhitneyU Testi Sonuçları

\begin{tabular}{lllllll}
\hline Ölçek & Grup & $\mathrm{N}$ & $\mathrm{S} \mathrm{O}$ & $\mathrm{S} \mathrm{T}$ & $\mathrm{U}$ & $\mathrm{p}$ \\
\hline Olumlu ilişkiler & Kız & 85 & 74,27 & 6313,00 & 2658 & .120 \\
& Erkek & 73 & 85,59 & 6248,00 & & \\
Uyumsuzluk & Kız & 85 & 84,75 & 7204,00 & 2656 & .118 \\
& Erkek & 73 & 73,38 & 5357,00 & & \\
Çatı̧̧ma & Kız & 85 & 79,35 & 6744,50 & 3089 & .964 \\
& Erkek & 73 & 79,68 & 5816,50 & & \\
ÇEİÖ-BF & Kız & 85 & 79,48 & 6756,00 & 3101 & .996 \\
& Erkek & 73 & 79,52 & 5805,00 & & \\
\hline
\end{tabular}

Tablo 2 incelendiğinde; bu araştırma kapsamında yapılan Mann Whitney-U testi sonucunda çocukların cinsiyetine göre babaların ÇEİÖ-B Formu ve alt boyutlarından aldıkları puanlar arasında anlamlı bir farklılık olmadığı görülmektedir ( $\mathrm{p}>.05)$.

Tablo 3.

Çocukların Doğum Sırasına Göre Babaların ÇEİÖ-B Formu ve Alt Boyutlarına İlişkin Kruskall Wallis Testi Sonuçları

\begin{tabular}{|c|c|c|c|c|c|c|c|}
\hline Ölçek & Grup & $\mathrm{N}$ & Sira Ortalaması & $\mathrm{Sd}$ & $X^{2}$ & $\mathrm{p}$ & Anlamlı fark \\
\hline \multirow{3}{*}{ Olumlu ilişkiler } & (A)İlk-tek çocuk & 45 & 76,86 & & & & \\
\hline & (B)Ortancalardan biri & 78 & 78,74 & 2 & 609 & .737 & \\
\hline & (C)Son çocuk & 35 & 84,60 & & & & \\
\hline \multirow[t]{3}{*}{ Uyumsuzluk } & (A)İlk-tek çocuk & 45 & 85,40 & & & & \\
\hline & (B)Ortancalardan biri & 78 & 80,62 & 2 & 2,515 & 284 & \\
\hline & (C)Son çocuk & 35 & 69,41 & & & & \\
\hline \multirow[t]{2}{*}{ Çatışma } & (A)ílk-tek çocuk & 45 & 95,20 & & & & C-A \\
\hline & (B)Ortancalardan biri & 78 & 74,59 & 2 & 7,680 & $.021 *$ & B-A \\
\hline
\end{tabular}




\begin{tabular}{lllllll}
\hline & (C)Son çocuk & 35 & 70,26 & & & \\
ÇEİÖ-BF & (A)İlk-tek çocuk & 45 & 89,31 & & & \\
& (B)Ortancalardan biri & 78 & 77,10 & 2 & 3,178 & .204 \\
& (C)Son çocuk & 35 & 72,24 & & & \\
\hline
\end{tabular}

Tablo 3'e bakıldığında çocukların doğum sırasına göre babaların ÇEïÖ-B Formu ve alt boyutlarından aldıkları puanlara ilişkin Kruskall Wallis testi sonuçları görülmektedir. Bu sonuçlara göre Çatışma alt boyutunda son çocuk ve ortanca çocuklardan biri ile ilk-tek çocuk arasında istatistiksel açıdan anlamlı bir fark olduğu görülmektedir $(\mathrm{p}<.05)$.

Tablo 4.

Çocukların Yaşına Göre Babaların ÇEİÖ-B Formu ve Alt Boyutlarına İlişkin Kruskall Wallis Testi Sonuçları

\begin{tabular}{llllllll}
\hline Ölçek & Grup & $\mathrm{N}$ & $\begin{array}{l}\text { Sira } \\
\text { Ortalaması }\end{array}$ & Sd & $\mathrm{X}^{2}$ & $\mathrm{p}$ & $\begin{array}{l}\text { Anlamlı } \\
\text { fark }\end{array}$ \\
\hline Olumlu & (A) 3-4 yaş & 74 & 72,37 & & & & \\
ilişkiler & (B) 4-5 yaş & 75 & 84,54 & 2 & 3,909 & .142 & \\
& (C) 5-6 yaş & 9 & 96,11 & & & & \\
Uyumsuzluk & (A) 3-4 yaş & 74 & 72,99 & & & & \\
& (B) 4-5 yaş & 75 & 84,57 & 2 & 2,986 & .225 & \\
& (C) 5-6 yaş & 9 & 90,78 & & & & \\
Çatışma & (A) 3-4 yaş & 74 & 78,36 & & & & \\
& (B) 4-5 yaş & 75 & 78,75 & 2 & 1,130 & .568 & \\
ÇEİÖ-BF & (C) 5-6 yaş & 9 & 95,17 & & & & \\
& (A) 3-4 yaş & 74 & 69,20 & & & & \\
& (B) 4-5 yaş & 75 & 85,98 & 2 & 9,355 & $.009 *$ & A-C \\
& (C) 5-6 yaş & 9 & 110,22 & & & & \\
\hline
\end{tabular}

Tablo 4'te çocukların yaş aralığ değişkenine göre babaların ÇEIÖ-B Formu ve alt boyutlarından aldıkları puanlara ilişkin Kruskall Wallis testi sonuçları yer almaktadır. Yapılan analizlere bakıldığında, ÇEİÖ- B Formundan alınan toplam puanlara göre babaların çocuklarıyla ilişkilerinde 3-4 yaş aralığındaki çocuklarıyla 5-6 yaş aralığındaki çocuklarına göre istatistiksel olarak anlamlı bir fark olduğu görülmektedir.

Tablo 5.

Babaların Yaşlarına Göre ÇEİÖ-B Formu ve Alt Boyutlarına İlişkin Kruskall Wallis Testi Sonuçları

\begin{tabular}{|c|c|c|c|c|c|c|c|}
\hline Ölçek & Grup & $\mathrm{N}$ & $\begin{array}{l}\text { Sira } \\
\text { Ortalamas1 }\end{array}$ & $\mathrm{Sd}$ & $\mathrm{X}^{2}$ & $\mathrm{p}$ & $\begin{array}{l}\text { Anlaml } \\
\text { fark }\end{array}$ \\
\hline Olumlu & (A) $20-29$ yaş & 25 & 73,92 & & & & \\
\hline \multirow{3}{*}{ ilişkiler } & (B) $30-39$ yaş & 74 & 83,81 & 3 & 4,965 & .174 & \\
\hline & (C) $40-49$ yaș & 42 & 83,70 & & & & \\
\hline & (D) 50 yaş ve üzeri & 17 & 58,56 & & & & \\
\hline \multirow[t]{4}{*}{ Uyumsuzluk } & (A) $20-29$ yaş & 25 & 76,30 & & & & \\
\hline & (B) $30-39$ yaş & 74 & 77,78 & 3 & 8,290 & .040 & C-D \\
\hline & (C) $40-49$ yaş & 42 & 72,52 & & & & \\
\hline & (D) 50 yaş ve üzeri & 17 & 108,91 & & & & \\
\hline \multirow[t]{4}{*}{ Çatışma } & (A) $20-29$ yaş & 25 & 105,72 & & & & \\
\hline & (B) $30-39$ yaş & 74 & 76,20 & 3 & 11,323 & .010 & D-A \\
\hline & (C) $40-49$ yaş & 42 & 68,25 & & & & C-A \\
\hline & (D) 50 yaş ve üzeri & 17 & 8312 & & & & \\
\hline \multirow[t]{4}{*}{ ÇEİÖ-BF } & (A) $20-29$ yaş & 25 & 90,68 & & & & \\
\hline & (B) $30-39$ yaş & 74 & 78,75 & 3 & 2,513 & .473 & \\
\hline & (C) $40-49$ yaş & 42 & 72,81 & & & & \\
\hline & (D) 50 yaş ve üzeri & 17 & 82,85 & & & & \\
\hline
\end{tabular}


Tablo 5 incelendiğinde; yapılan Kruskall Wallis testi sonucunda babaların yaş aralığına göre ÇEIÖÖB Formu ve alt boyutlarından aldıkları puanlar arasında, Uyumsuzluk ve Çatışma alt boyutunda istatistiksel olarak anlamlı bir farkl11ı olduğu görülmektedir $(\mathrm{p}<.05)$. Bu farklılığın Uyumsuzluk alt boyutunda 40-49 yaş ile 50 yaş ve üzeri babalar arasında, 40-49 yaş arasındaki babalar lehine; Çatı̧̧ma alt boyutunda ise 50 yaş ve üzeri babalar ile 20-29 yaş arasındaki babalar arasında, 50 yaş ve üzeri babalar lehine ve 40-49 yaş arasındaki babalar ile 20-29 yaş arasındaki babalar arasında 40-49 yaş arasındaki babalar lehine olduğu belirlenmiştir.

Tablo 6.

Babaların Öğrenim Durumlarına Göre ÇEİÖ-B Formu ve Alt Boyutlarına İlişkin Kruskall Wallis Testi Sonuçları

\begin{tabular}{llllllll}
\hline Ölçek & Grup & N & $\begin{array}{l}\text { Sira } \\
\text { Ortalaması }\end{array}$ & Sd & $X^{2}$ & p & $\begin{array}{l}\text { Anlamlı } \\
\text { fark }\end{array}$ \\
\hline Olumlu & (A) İlkokul mezunu & 43 & 67,56 & & & & \\
ilişkiler & (B) Ortaokul mezunu & 44 & 87,89 & 4 & 17,231 & .002 & E-B \\
& (C) Lise mezunu & 36 & 95,60 & & & & E-C \\
& (D) Üniversite mezunu & 14 & 89,71 & & & & \\
& (E) Lisansüstü mezunu & 21 & 51,98 & & & & \\
Uyumsuzluk & (A) İlkokul mezunu & 43 & 83,69 & & & & \\
& (B) Ortaokul mezunu & 44 & 77,51 & 4 & 1,381 & .847 & \\
& (C) Lise mezunu & 36 & 73,21 & & & & \\
& (D) Üniversite mezunu & 14 & 83,75 & & & & \\
& (E) Lisansüstü mezunu & 21 & 83,05 & & & & \\
Çatışma & (A) İlkokul mezunu & 43 & 75,34 & & & \multirow{2}{*}{019} & E-B \\
& (B) Ortaokul mezunu & 44 & 70,78 & 4 & 11,729 & .019 & \\
& (C) Lise mezunu & 36 & 74,94 & & & & \\
& (D) Üniversite mezunu & 14 & 86,43 & & & & \\
ÇEİÖ-BF-BF & (E) Lisansüstü mezunu & 21 & 109,48 & & & & \\
& (A) İlkokul mezunu & 43 & 68,10 & & & \multirow{2}{*}{.295} & \\
& (B) Ortaokul mezunu & 44 & 79,31 & 4 & 4,927 & & \\
& (C) Lise mezunu & 36 & 84,29 & & & & \\
& (D) Üniversite mezunu & 14 & 94,75 & & & & \\
& (E) Lisansüstü mezunu & 21 & 84,86 & & & & \\
\hline
\end{tabular}

Tablo 6'da babaların öğrenim durumuna göre ÇEİÖ-B Formu ve alt boyutlarından aldıkları puanlara ilişkin Kruskall Wallis testi sonuçları görülmektedir. Elde edilen bulgulara göre ÇEIÖ- B Formu'nun Olumlu İlişkiler ve Çatışma alt boyutunda istatistiksel olarak bir fark olduğu tespit edilmiştir $(\mathrm{p}<.05)$. Bu durumda, Olumlu ilişkiler alt boyutunda Lisansüstü mezunu babaların Ortaokul ve Lise mezunu babalara göre çocuklarıyla daha olumlu ilişkilere sahip olduğu, Çatı̧̧ma alt boyutunda ise Lisansüstü mezunlarının Ortaokul mezunlarına göre çocuklarıyla daha az çatışma yaşadığ söylenebilir.

Tablo 7.

Babaların evliliklerini nasıl değerlendirdikleri değişkenine göre ÇEİÖ-B Formu ve alt boyutlarına ilişkin Kruskall Wallis testi sonuçları

\begin{tabular}{|c|c|c|c|c|c|c|}
\hline Ölçek & Grup & $\mathrm{N}$ & $\begin{array}{l}\text { Sira } \\
\text { Ortalamas1 }\end{array}$ & $\mathrm{Sd}$ & $\mathrm{X}^{2}$ & $\mathrm{p}$ \\
\hline \multirow{3}{*}{$\begin{array}{l}\text { Olumlu } \\
\text { ilişkiler }\end{array}$} & Oldukça uyumlu & 33 & 80,32 & \multirow{3}{*}{2} & \multirow{3}{*}{.048 } & \multirow[b]{2}{*}{976} \\
\hline & $\begin{array}{l}\text { Zaman } \\
\text { çatışmalı }\end{array}$ & 95 & 78,91 & & & \\
\hline & Uyumsuz, mutsuz & 29 & 77,81 & & & \multirow{4}{*}{.518} \\
\hline \multirow[t]{3}{*}{ Uyumsuzluk } & Oldukça uyumlu & 33 & 86,83 & \multirow{3}{*}{2} & \multirow{3}{*}{1,314} & \\
\hline & $\begin{array}{l}\text { Zaman } \\
\text { çatışmalı }\end{array}$ & 95 & 77,48 & & & \\
\hline & Uyumsuz, mutsuz & 29 & 75,05 & & & \\
\hline
\end{tabular}




\begin{tabular}{|c|c|c|c|c|c|c|}
\hline \multirow[t]{3}{*}{ Çatışma } & Oldukça uyumlu & 33 & 80,30 & \multirow[b]{2}{*}{2} & \multirow[b]{2}{*}{.766} & \multirow[b]{2}{*}{.682} \\
\hline & $\begin{array}{l}\text { Zaman zaman } \\
\text { çatışmalı }\end{array}$ & 95 & 76,73 & & & \\
\hline & Uyumsuz, mutsuz & 29 & 8495 & \multirow{4}{*}{2} & \multirow{4}{*}{.567} & \multirow{4}{*}{.753} \\
\hline \multirow[t]{3}{*}{ ÇEİÖ-BF } & Oldukça uyumlu & 33 & 83,73 & & & \\
\hline & $\begin{array}{l}\text { Zaman zaman } \\
\text { çatışmalı }\end{array}$ & 95 & 76,98 & & & \\
\hline & Uyumsuz, mutsuz & 29 & 80,22 & & & \\
\hline
\end{tabular}

Tablo 7 incelendiğinde; yapılan Kruskall Wallis testi sonucunda babaların evliliklerini nasıl değerlendirdikleri değişkenine göre ÇEİÖ-B Formu ve alt boyutlarından aldıkları puanlar arasında anlamlı bir farklılık olmadığı görülmektedir ( $\mathrm{p}>.05)$.

Tablo 8.

Babaların evlilik sürelerine göre ÇEIÖ-B Formu ve alt boyutlarına ilişkin Kruskall Wallis testi sonuçları

\begin{tabular}{|c|c|c|c|c|c|c|c|}
\hline Ölçek & Grup & $\mathrm{N}$ & $\begin{array}{l}\text { Sira } \\
\text { Ortalamas1 }\end{array}$ & $\mathrm{Sd}$ & $\mathrm{X}^{2}$ & $\mathrm{p}$ & $\begin{array}{l}\text { Anlamlı } \\
\text { fark }\end{array}$ \\
\hline Olumlu & (A) 5 yil ve daha az & 40 & 91,98 & & & & \\
\hline \multirow[t]{4}{*}{ ilişkiler } & (B) 6-10 y1l & 44 & 80,99 & 4 & 7,917 & .095 & \\
\hline & (C) $11-15$ y1l & 19 & 77,37 & & & & \\
\hline & (D) $16-20$ y1l & 22 & 81,77 & & & & \\
\hline & (E) 21 yıl ve üzeri & 33 & 62,11 & & & & \\
\hline \multirow[t]{5}{*}{ Uyumsuzluk } & (A) 5 yil ve daha az & 40 & 75,24 & & & & \\
\hline & (B) $6-10$ y1l & 44 & 77,76 & 4 & 5,750 & .219 & \\
\hline & (C) $11-15$ y1l & 19 & 66,89 & & & & \\
\hline & (D) $16-20$ y1l & 22 & 98,48 & & & & \\
\hline & (E) 21 yıl ve üzeri & 33 & 81,59 & & & & \\
\hline \multirow[t]{5}{*}{ Çatışma } & (A) 5 yil ve daha az & 40 & 83,11 & & & & \\
\hline & (B) 6-10 y1l & 44 & 99,24 & 4 & 32,588 & .000 & D-B \\
\hline & (C) $11-15$ y1l & 19 & 103,32 & & & & $\mathrm{D}-\mathrm{C}$ \\
\hline & (D) $16-20 \mathrm{y} 1 \mathrm{l}$ & 22 & 50,30 & & & & \\
\hline & (E) 21 yıl ve üzeri & 33 & 54,56 & & & & \\
\hline \multirow[t]{5}{*}{ ÇEİÖ-BF } & (A) 5 yil ve daha az & 40 & 93,30 & & & & E-C \\
\hline & (B) $6-10$ y1l & 44 & 93,20 & 4 & 26,487 & .000 & E-B \\
\hline & (C) $11-15$ y1l & 19 & 87,11 & & & & E-A \\
\hline & (D) $16-20 \mathrm{y} 1 \mathrm{l}$ & 22 & 70,20 & & & & \\
\hline & (E) 21 yıl ve üzeri & 33 & 46,32 & & & & \\
\hline
\end{tabular}

Tablo 8'e bakıldığında babaların evlilik sürelerine göre ÇEİÖ-B Formu ve alt boyutlarından aldıkları puanlara ilişkin Kruskall Wallis testi sonuçları görülmektedir. Elde edilen bulgulara göre ÇEİÖ- B Formu'nun toplamında ve Çatışma alt boyutunda istatistiksel olarak bir fark olduğu tespit edilmiştir $(\mathrm{p}<.05)$. Bu farkl1lığın ÇEİÖ-B Formu'nda 21 yıl ve üzeri evli olanlar ile 5yıl ve daha az, 6-10 yıl arası ve 11-15 yıl arası evli olanlar arasında 21 yıl ve üzeri evli olanların lehine; Çatı̧̧ma alt boyutunda ise 16-20 yıl arası evli olanlar ile 6-10 yıl arası ve 11-15 yıl arası evli olanlar arasında 16-20 yıl arası evli olanların lehine olduğu görülmektedir.

Tablo 9'da araştırmaya dahil edilen babaların ve eşlerinin çalışma durumlarına göre babaların ÇEİÖ-B Formu ve alt boyutlarından aldıkları puanlara ilişkin Kruskall Wallis testi sonuçları görülmektedir. Bu sonuçlara göre babaların ölçeğin toplamı ve alt boyutlarından aldıkları puanlar arasında istatistiksel olarak anlamlı bir fark olmadığı görülmektedir ( $p>.05$ ). Başka bir deyişle araştırmaya katılan babaların ve eşlerinin sürekli çalışıyor, çalışmıyor ya da zaman zaman çalışıyor olmalarının baba çocuk ilişkisi üzerinde herhangi bir etkisinin olmadığ 1 söylenebilir. 
Tablo 9.

Anne ve babaların çalışma durumuna göre babaların ÇEIÖ-B Formu ve alt boyutlarına ilişkin Kruskall Wallis testi sonuçları

\begin{tabular}{|c|c|c|c|c|c|c|}
\hline $\begin{array}{l}\text { Ölçek/Alt } \\
\text { Boyutlar }\end{array}$ & Grup (Anne) & $\mathrm{N}$ & $\begin{array}{l}\text { Sira } \\
\text { Ortalamas1 }\end{array}$ & $\mathrm{Sd}$ & $\mathrm{X}^{2}$ & $\mathrm{p}$ \\
\hline Olumlu & Sürekli çalıșıyor & 43 & 85,76 & & & \\
\hline \multirow[t]{2}{*}{ ilişkiler } & Zaman zaman çalışıyor & 58 & 72,10 & 2 & 2,545 & .280 \\
\hline & Çalışmıyor & 57 & 82,31 & & & \\
\hline \multirow[t]{3}{*}{ Uyumsuzluk } & Sürekli çalışıyor & 43 & 74,01 & & & \\
\hline & Zaman zaman çalışıyor & 58 & 78,93 & 2 & 1,244 & .537 \\
\hline & Çalıșmıyor & 57 & 84,22 & & & \\
\hline \multirow[t]{3}{*}{ Çatışma } & Sürekli çalışıyor & 43 & 78,98 & & & \\
\hline & Zaman zaman çalışıyor & 58 & 79,87 & 2 &, 010 & .995 \\
\hline & Çalışmıyor & 57 & 79,52 & & & \\
\hline \multirow[t]{4}{*}{ ÇEİÖ-BF } & Sürekli çalışıyor & 43 & 81,00 & & & \\
\hline & Zaman zaman çalışıyor & 58 & 71,75 & 2 & 2,965 & .227 \\
\hline & Calıșmiyor & 57 & 86,25 & & & \\
\hline & Grup (Baba) & & & & & \\
\hline Olumlu & Sürekli çalıșıyor & 97 & 83,22 & & & \\
\hline \multirow{2}{*}{ ilişkiler } & Zaman zaman çalışıyor & 54 & 74,14 & 2 & 1,740 & .419 \\
\hline & Çalıșmıyor & 7 & 69,14 & & & \\
\hline \multirow[t]{3}{*}{ Uyumsuzluk } & Sürekli çalışıyor & 97 & 73,61 & & & \\
\hline & Zaman zaman çalışıyor & 54 & 88,00 & 2 & 4,369 & .113 \\
\hline & Çalışmıyor & 7 & 95,57 & & & \\
\hline \multirow[t]{3}{*}{ Çatışma } & Sürekli çalışıyor & 97 & 83,36 & & & \\
\hline & Zaman zaman çalıșıyor & 54 & 73,31 & 2 & 1,802 & .406 \\
\hline & Çalıșmiyor & 7 & 73,71 & & & \\
\hline \multirow[t]{3}{*}{ ÇEİÖ-BF } & Sürekli çalışıyor & 97 & 81,60 & & & \\
\hline & Zaman zaman çalışıyor & 54 & 74,52 & 2 & 1,142 & .565 \\
\hline & Calısmiyor & 7 & 88,86 & & & \\
\hline
\end{tabular}

\section{Tartışma ve Sonuç}

$\mathrm{Bu}$ araştırmadan elde edilen bulgular sonucunda, babaların çocuklarıyla ilişkisinde çocuğun cinsiyeti, babaların evliliklerini nasıl değerlendirdikleri (oldukça uyumlu, uyumsuz ve mutsuz ya da zaman zaman çatışmalı) ve baba ve annenin çalışma durumu açısından gruplar arasında anlamlı bir farklılık olmadığg görülmektedir ( $\mathrm{p}>.05$ ). Ancak çocuğun doğum sırası, çocuğun yaşı, babanın yaşı, babanın öğrenim durumu ve evlilik süresine ilişkin puanlarda gruplar arasında istatistiksel olarak anlamlı farklılık olduğu görülmüştür $(\mathrm{p}<.05)$.

Bireyin içinde yaşadığı ailenin tutum ve davranışlarını gelişimini doğrudan etkilenmektedir. Bu tutum ve davranışların içeriği bireyin doğum sırasıyla ilişkilendirilebilir. Örneğin ilk doğan ve tek olan çocuklar aile içinde benzersiz bir konuma sahip olabilirler; anne ve babalar ilk ve tek çocuklarına daha çok vakit ayırıp daha çok ilgi gösterebilirler. Erişkin davranış ve tutumlarını sergileyebilir, böylece daha sorumlu, işbirliğine eğilimli olabilirler. Yapılan araştırmalar doğum sırasının kişilik üzerindeki etkilerini desteklemektedir (Atkinson ve diğerleri, 1995). Benzer bir şekilde, Özyürek ve Tezel-Şahin (2005) yaptıkları araştırmada anne ve baba tutumlarının çocuğun doğum sırası ve kardeş sayısından etkilendiği tespit etmişlerdir. Hamamcı ve Köksal-Akyol (2004), babaların yeterlilik algılarında çocuk sayısının disiplin ve çocuğun davranışlarını yönlendirme, aile içi iletişim, fiziksel gelişim, sağlık ve beslenme, genel kişilik gelişimi ve oyun ve oyun materyallerinin önemi konularında anlamlı farklılığa neden olduğunu belirtmişlerdir. İnci ve Deniz (2015) baba tutumlarının çocuğun doğum sırasına göre farklılık gösterdiğini ortaya koymuşlardır. $\mathrm{Bu}$ araştırmada babaların son ve ortanca çocuklarıyla iliş̧kilerinde ilk çocuklara göre daha az çatışma yaşadıkları tespit edilmiştir. Mevcut çalışmanın bulgularına dayanarak, çocuk yaşının baba çocuk ilişkisine etkisi olduğu görülmektedir $(p<.05)$. $\mathrm{Bu}$ farklılık ÇEİÖ-B Formu'nun toplamından elde edilen puanlar için 3-4 yaş arasındaki çocuklarla 5-6 yaş çocuklar arasında 3-4 yaşındaki çocuklar lehine ortaya çıkmaktadır. Arabacı 
ve Ömeroğlu (2013) yaptıkları araştırmada baba çocuk ilişkisinde önemli bir yere sahip olan baba çocuk iletişiminde, babaların sözsüz iletişimde 61-72 ay arasında ki çocuklara göre 48- 60 aylık, düşük yaş grubundaki çocuklar lehine bir farklılık olduğunu tespit etmiş ve babaların, sevgi, ilgi ve şefkate daha fazla gereksinim duymalarından dolayı, küçük yaştaki çocuklarına daha yakın davranışlar içerisinde bulunmalarından kaynaklanmış olabileceğini belirtmişlerdir. Levin ve Currie (2010) tarafindan yapılan çalışmada, örneklemde yer alan küçük yaş grubundaki çocukların kendilerini mutlu hissetmeleri ve yaşamlarından hoşnutluk duymaları ile baba-çocuk iletişimi arasında bir bağlantı bulunduğu belirlenmiştir. Dolayısıyla araştırmada ortaya konulan sonuçlar ile literatürdeki bazı çalışmaların birbirine benzer sonuçlar ortaya koyduğu görülmektedir.

Araştırma sonuçlarına göre babanın yaşı, öğrenim durumu ve evlilik süresi değişkenlerine ilişkin ÇEIÖ-BF ve alt boyutlarından aldıkları puanlarda istatistiksel olarak anlamlı bir farklılık olduğu görülmektedir $(\mathrm{p}<.05)$. Araştırmada babaların çocuklarıyla ilişkilerinde babanın yaşı değişkenine ilişkin puanlar gözönüne alındığında Uyumsuzluk ve Çatışma alt boyutlarında istatistiksel olarak anlamlı fark olduğu görülmektedir ( $\mathrm{p}<.05)$. Ünlü (2010) tarafindan gerçekleştirilen çalışmada 0-8 yaş aralığında çocuğu olan babaların ve onların babalarının çocuk bakımına katılımlarının genel yapısı, babaların oğullarının babalık davranışlarına etkisi ve babanın çocuğun bakımına katılımını etkileyen faktörlerin incelenmesi amaçlanmış ve babanın yaşının, baba çocuk ilişkisinde önemli bir yere sahip olan çocuğunun bakımına katılma düzeyini etkilediği belirlenmiştir. Babanın öğrenim durumu değişkenine göre; ÇEIÖ-B Formu'nun Olumlu ilişkiler alt boyutunda, lisansüstü mezunu babalar ile ortaokul ve lise mezunu babalar arasında ve Çatışma alt boyutunda lisansüstü mezunu babalar ile ortaokul mezunu babalar arasında istatistiksel olarak anlamlı bir fark olduğu görülmektedir $(\mathrm{p}<.05)$. Bu durum babanın eğitim seviyesindeki artışın baba ile çocuk arasındaki ilişkiyi olumlu yönde etkilediği ve çatışmaları azalttığı şeklinde yorumlanabilir. Günindi (2008) anne babaların öğrenim düzeylerinin yüksek olmasının çocukların sosyal uyum becerilerini olumlu yönde etkilediği tespit edilmiştir. Ayrıca araştırmada evlilik süresindeki artışı baba çocuk arasındaki ilişkiyi olumlu etkilediğini göstermiştir. Bu farklılığın ÇEİÖ-B Formu'nda 21 yıl ve üzeri evli olanlar ile 5 y1l ve daha az, 610 yıl arası ve 11-15 yıl arası evli olanlar arasında 21 yıl ve üzeri evli olanların lehine, Çatışma alt boyutunda ise 16-20 y1l aras1 evli olanlar ile 6-10 y1l aras1 ve 11-15 y1l aras1 evli olanlar arasında 16-20 yıl arası evli olanların lehine olduğu tespit edilmiştir. Bunun nedeni babaların yaşı, öğrenim düzeyi ve evlilik süresi arttıkça babalık konusundaki tecrübelerini artırması ve bu deneyimlerin babalık becerilerinin gelişmesine katkıda bulunması olabilir. Yapılan araştırmalara göre evlilik süresi, evlilik uyumunu etkilemektedir. Evliliğin ilk yıllarında evlilik uyumunun düşük olduğuna ancak, evlilik süresi ilerleyip çocuklar evden ayrıldıktan sonra daha yükseldiğine ilişskin araştırma sonuçları bulunmaktadır (Anderson ve diğerleri, 1983). Benzer bir şekilde Spainer ve arkadaşları (1995) yaptıkları araştırmada evliliğin ilk yıllarında evlilik uyumunun daha düşük olduğunu, ilerleyen yıllarda ise yükseldiğini saptamışlardır. Evlilik süresinin, cinsiyetler açısından evlilik uyumunu nasıl etkilediğine ilişkin araştırmalarda ise, kadınlarda evlilik uyumunun evlilik süresi arttıkça düştüğü, erkeklerde ise yükseldiği belirlenmiştir (Houseknecht ve Macke, 1981). Shapiro (1996) çalışmasında, boşanmanın babaların çocuklarıyla sağlıklı ilişki kurma kalitesini düşürdüğünü belirtmektedir. Dolayısıyla ilgili literatür çerçevesinde anne babanın evli olması ya da evlilik süresinin uzun olması babaların çocuklarıyla olan ilişkilerini olumlu yönde etkilediği söylenebilir.

\section{Öneriler}

Araştırmadan elde edilen sonuçlar doğrultusunda, uzmanlar (eğitimciler, çocuk gelişimcileri ve çocuklarla çalışan diğer uzmanlar) baba çocuk ilişkisinin niteliğini artırmak amacıyla, babaların katılımını sağlayan ve babaların dahil olduğu aktiviteler planlayabilir. Bununla birlikte, okul içinde ve dışında, babaların katılabilecekleri eğitim etkinlikleri veya alan gezileri gibi çocuklar üzerinde olumlu ve kalıcı etki sağlayabilecek etkinlikler gerçekleştirebilirler. Ayrıca babalara yönelik makale kutusu, broşür, afiş, seminer, konferans gibi aile katılım çalışmalarının düzenlenmesi önerilebilir. Çeşitli aile katılım çalışmaları aracılığıyla velilerle işbirliği 
geliştirebilir ve anne baba çocukların daha etkin ve kalıcı öğrenmelerini sağlanabilir. Ayrıca, baba çocuk ilişkisi düzeyini geliştirmek için okul öncesi dönemde oyun, drama, serbest zaman, müzik ve sanat etkinlikleri gibi farklı etkinliklerde babaların da katılımını sağlayacak düzenlemeler yapılabilir. Bununla birlikte bu alanda çalışan araştırmacılar, babaların çocuklarıyla ilişki düzeylerini artırmak amacıyla okul öncesi eğitim döneminden sonraki eğitim basamakları için de eğitim programları ya da eğitim etkinlikleri düzenleyebilir.

Bu araştırma Güneydoğu Anadolu Bölgesi'nde Kilis ilinde yaşayan babalar ve çocukları ile yürütülmüştür. İlgili araştırmacılar benzer bir çalışmayı farklı bölge ve illerde farklı demografik ve sosyo- ekonomik düzeydeki babalar ve çocuklarla gerçekleştirebilir.

\section{Kaynaklar}

Anderson, S. A., Russel W. R. ve Schumm, J. (1983). Perceived marital quality and family lifecycle categories: a further analysis. Journal of Marriage and the Family, 45(2), 127-139.

Arabacı, N. ve Ömeroğlu, E. (2013). 48-72 Aylık Çocuğa Sahip Anne-Babaların Çocukları İle İletişimlerinin BazıDeğişkenler Açısından İncelenmesi. Selçuk Üniversitesi Sosyal Bilimler Enstitüsü Dergisi, (30), 41-53.

Atkinson, R. L., Atkinson, R. C. ve Hilgard, R. E. (1995). Psikolojiye giriş. K. M. Atakay ve A. Yavuz (Çev.). İstanbul: Sosyal Yayınları.

Bronstein, M. H. ve Zlotnik, D. (2008). Parenting styles and their effects: Infant and early childhood development. M. M. Haith ve J. B. Benson (Yay. haz.), içinde (ss. 496-509), Elsevier, Oxford.

Büyüköztürk, Ş. (2011). Sosyal Bilimler İçin Veri Analizi El Kitabı. Pegem Akademi, Ankara

Can-Toprakçı, N. (2006). Kurumda ĕgitim alan zihinsel engelli öğrencilerin annelerine genişletilmiş aile eğitim programının uygulanmasının öğrencilerin matematik ders amaçlarını edinmelerinde, sürdürme ve genellemelerine etkisi (Yayımlanmamış yüksek lisans tezi), Gazi Üniversitesi. Ankara.

Çağdaş, A. (2008). Anne-baba-çocuk iletişimi. Kök Yayıncılık, Ankara.

Diler-Sönmez, N. (2008). Eve dayalı gündüz tuvalet kontrolü aile eğitimi programının anneler ve zihinsel engelli çocuklarında beklenen davranış değişikliklerini gerçekleştirmede etkisi. (Yayımlanmamış doktora tezi). Gazi Üniversitesi, Ankara.

Erkan, S. ve Durmuş̧oğlu, M. C. (2006). Anne eğitimi programının annenin çocuk yetiştirme tutumlarına etkisinin incelenmesi. Avrupa Birliği Sürecinde Okul Öncesi Eğitimin Geleceği Sempozyumu, Ya-Pa Yayın Pazarlama, 349-360, İstanbul.

Gordon, T. (2009). Etkili Anne-Baba Ĕgitimi (2. Basım). D. Tekin ve N. Özkan (Çev.). İstanbul: Profil Yayıncilık.

Güngörmüş-Özkardeş, O. (2006). Baba ve çocuk. İstanbul: Morpa Kültür Yayınları.

Günindi, N. (2008). Okul öncesi eğitim kurumlarına devam eden altı yaş çocuklarının sosyal uyum becerileri ile anne-babalarının empatik becerileri arasındaki ilişkinin incelenmesi. (Yayımlanmamış yüksek lisans tezi). Gazi Üniversitesi Eğitim Bilimleri Enstitüsü, Ankara.

Hamamcı, Z. ve Köksal-Akyol, A. (2004). 3-6 yaşlarında çocukları olan anne babaların eğitim gereksinimlerinin belirlenmesi. Dünya Konsey Toplantısı ve Konferansı Bildiri Kitabı 1, 5-11 Ekim 2003. Yapa Yayınları içinde (ss. 136-148). İstanbul.

Heinowitz, J. (1998). İmdat baba oldum. Ç. Sungur (Çev.). Beyaz Yayınları İstanbul.

Ho, Y. F. ve Lamb, M. E. (1987). The father's role: Cross-cultural perspective. Erlbaum.

Houseknecht, S. K. ve Macke, A. S. (1991). Combining marriage and career: the marital adjustment of professional women. Journal of Marriage and the Family, 43, 651-661.

İnci, M. A. ve Deniz, Ü. (2015). Baba tutumları ile çocuğun yaşı, cinsiyeti, doğum sırası ve kardeş sayısı değişkenleri arasındaki ilişkinin incelenmesi. Karadeniz Sosyal Bilimler Dergisi, $7(02)$.

Karasar, N. (2008). Bilimsel araştırma yöntemi: kavramlar-ilkeler-teknikler. Ankara: Nobel Yayın Dağıtım. 
Kaya, Ö. M. (2002). Okul öncesi eğitim kurumlarında uygulanan programlara ailelerin ilgi ve katılımları ile okul öncesi eğitim kurumlarının aile eğitimine katkısı konusunda annebaba görüşleri (Yayımlanmamış yüksek lisans tezi). Anadolu Üniversitesi, Eğitim Bilimleri Enstitüsü, Eskişehir.

Koçak, A. A. (2004). Baba destek programı değerlendirme raporu. Erişim adresi: www.acev.org/ kaynaklarimiz/arastirmalarimiz-ve-yayinlarimiz.

Levin, K. A. ve Currie, C. (2010). Family structure, mother-child communication, father-child communication, and adolescent life satisfaction: A cross-sectional multilevel analysis. Health Education, 110(3), 152-168.

Mahoney, G., Kaiser, A., Girolameto, L., Macdonald, J., Robinson, C. Safford, P. ve Spiker, D. (1999). Parent education in early invervention: A call for a renewel focus. Topics in Early Childhood Education, 19(3), 131-140.

Morrison, G. S. (2006). Fundamentals of early childhood education. Pearson Prentice Hall, Fourth Edition, New Jersey.

Öz, İ. (2005). Çocuk ve iletişim. KÖK Yayıncılık, Ankara.

Özyürek, A. ve Tezel-Şahin, F. (2005). 5 ve 6 Yaş grubunda çocuğu olan ebeveynlerin tutumlarının incelenmesi. Gazi Üniversitesi Gazi Eğitim Fakültesi Dergisi, 25(2).

Pianta, R. C. (1992). Child-parent relationship scale. University of Virginia

Riley, R. W., Peterson, T. K., Moreno, M. G. ve Goode, W. W. (2000). Strengthening participation of fathers in children's learning and devolepment, father's mother involving fathers in children's learning. A kit for educators and other professionals, USA.

Rusell, G. ve Rusell, A. (1987). Mother-child and father-child relationships in middle childhood. Child Development, 58, 1573-1585.

Segrin C. ve Flora, J. (2005). Family communication. Lawrence Erlbaum Associates, Publishers, London.

Shapiro, A. D. (1996). Marital status transitions, father-child relationships, and fathers' psychological well-being (Doctoral dissertation). University of Texas, Austin.

Spainer, G. B., Lewis, R. A. ve Cole, C. L. (1995). Marital adjustment over the family life cycle: the 1ssue of curvilinearity. Journal of Marriage and the Family, 37, 263-275.

Tezel-Şahin, F. ve Özyürek, A. (2010). Anne baba eğitimi ve okul öncesinde aile katılımı. Morpa Kültür Yayınları, İstanbul.

Uzun, H. ve Baran, G. (2015). Çocuk Ebeveyn İlişki Ölçeği'nin okul öncesi dönemde çocuğu olan babalar için geçerlik ve güvenirlik çalışması. Uluslararası Ĕgitim Bilimleri Dergisi, $2(3), 30-40$

Üstünoğlu Ü. (1991). Aile eğitiminde uygulanabilecek farklı yaklaşımlar. Aile eğitim paneli. Başbakanlık Aile Araştırma Kurumu Başkanlığı, 82-88, Ankara.

Varol N. (2005). Aile eğitimi (4. Basım). Kök Yayıncılık, Ankara.

Wong, S. Y., Lai, A. C., Martinson, I. ve Wong, T. K. S. (2006). Effects of education rogramme on family participation in the rehabilitation of children. Journal of Intellectual Disabilities, 10(2), 165-189.

Yılmaz-Bolat, E., Gürsoy, F. ve Strom, R. (2016). Öğretmen olarak anne baba envanteri: geçerlik ve güvenirlik çalışması. Mersin Üniversitesi Eğitim Fakültesi Dergisi, 12(3).

\section{Extended Abstract}

\section{Introduction}

In order to become as healthy adults, it is necessary for children to grow up in a family having healthy relations (Erkan and Durmuşoğlu, 2006). Being a strong determiner for the wrong and well doings of the children in his developmental period, family influences the development and learnings of the children in depth (Morrison, 2006). It is very well-known that it is very difficult to reach desired level unless the parents are involved in educational period. That's why, the importance attached to family training has been increasing in recent years (Can Toprakçı, 2006; Diler Sönmez, 2008; Varol, 2005). Family education is defined as the activities aiming to ensure 
that parents are able to raise their children in a healthy manner, in order to provide a richly stimulating home environment to support the parents and the child-rearing person, to realize parent-child communication and to respond to the development of the child from birth to the beginning of primary school (Mahoney et al., 1999; Wong et al., 2006; Üstünoğlu, 1991). In human life, social, political, economic, cultural and scientific factors determine how the father fulfils his paternal role. Since all these factors are not static but changing, it is seen that the fatherhood roles also show differences. As a matter of fact, the studies on the parenthood began in the early 1980s, but in the 1990s this issue started to be widely discussed internationally. Paternal Participation Typology by Lamb has established an important theoretical background for the studies on the effects of fathers on child development. Lamb reveals three important dimensions of father participation. The first of these is the interaction that expresses the time spent by the fathers with their children. The second is accessibility, expressing emotional and physical closeness and expressing time to the child's priorities, and, last but not least, taking responsibility for the healthy development and happiness of the child (Koçak, 2004; Lamb, 1987).

Interaction (Direct Contact): It covers every kind of activity that your father has a direct, individual relationship with his child. This kind of participation can be exemplified by travelling with children, talking, playing and being together.

Accessibility: It means for the father being both physically and psychologically accessible for the child. The accessibility of the father means that the child can receive support from his father when he needs it. Children's feeling of being able to reach their fathers and to be with them positively affects their confidence.

Responsibility: It includes such activities as taking the child to a doctor or organizing the meeting with their friends, or to remember and planning to do some activities for the child. It often also means supporting the mother (Koçak, 2004). The model laid out by Lamb has created the infrastructure for many of the work and programs developed for the father, and in recent years has led to an increasing interest in the literature on the role and effects of poverty on child development. It is possible to rank the factors that are effective in increasing this interest and changing the paternal role against the fathers are the increase in the number of women having higher education and working at a full day work, increase in divorce rates and changing roles and responsibilities of individuals, as a result of the traditional families turning into nuclear families (Güngörmüş Özkardeş, 2006; Heinowitz, 1998).

Bronstein and Zlotnik (2008) stress that the father-child relationship is different from the mother-child relationship both in nature and quantity. The researchers propound that the father is particularly important for boys to adopt masculine behaviours, and boys learn to behave like a man by identifying with their fathers. Accordingly, it can be suggested that the nature of the father-child relationship plays a significant role in supporting the child's development in many areas. For these reasons, this study aimed at exploring the impact of a training program prepared for fathers with children attending preschool on the father-child relationship.

\section{Method}

This study intended to explain the relationship between fathers and their children attending preschool according to the views and attitudes of the fathers. In this context, the survey study design was used in the research. Survey study design is a research approach aimed at providing a description of a given situation in the past or present time as it is (Karasar, 2008). The research sample consisted of 158 fathers who had children attending public preschools under the Ministry of National Education in Kilis province, Turkey, and participated in the study voluntarily. For selecting the sample, random sampling method was employed. To collect data, the study used the Child-Parent Relationship Scale (Father Form) that was tested for validity and reliability in Turkish by Uzun and Baran (2015). To prepare the Child-Parent Relationship Scale that was originally developed by Pianta (1992), the study drew on the literature on the parent-child interaction, attachment theory and the Attachment Q-Set. 


\section{Result and Discussion}

The findings of the study indicated that there was no significant difference between the groups in relation to the child's gender, how the fathers considered their marriage (quite harmonious, mismatched and unhappy or with occasional conflicts) and employment status of the father and mother in terms of the fathers' relationship with their children ( $>$ >.05). However, a statistically significant difference was observed between the groups in the scores regarding the child's birth order, the child's age, the father's age, the father's educational background and marriage duration $(\mathrm{p}<.05)$.

The study found that the fathers experienced less conflict in their relations with last-born and middle children compared to the first-borns. The findings of the present study revealed that the child's age has an impact on the father-child relationship $(p<.05)$. Such difference was manifested itself between the children aged 3-4 years old and children aged 5-6 years old for the total scores on the CPRS-F Form in favour of the children who were 3-4 years old.

According to the results of the study, there was a statistically significant difference in the scores on the CPRS-FF and its factors for the father's age, father's educational background and marriage duration variables $(\mathrm{p}<.05)$. Based on the scores for "the father's age variable in the father's relationship with his children, a statistically significant difference was observed in Incompatibility and Conflict factors ( $\mathrm{p}<.05)$.

With regard to the father's educational background, there were statistically significant differences between the fathers with postgraduate education and the fathers who graduated from secondary school or high school for Positive Relationships, and between the fathers with postgraduate education and secondary school graduates for Conflict in the CPRS-F Form ( $\mathrm{p}<.05)$. This result can be interpreted that the increase in the level of education of fathers had a positive impact on the relationship between the father and child, and reduced conflicts. The study also demonstrated that increase in marriage duration had a positive effect on the father-child relationship. The difference was found between the fathers married for $21+$ years, and those married for 5 years or less, those married for 6-10 years and those married for 11-15 years in favour of those married for 21+years in the CPRS-F Form; and between the fathers who were married for 16-20 years, and those married for 6-10 years and for 11-15 years in favour of those married for 16-20 years for Conflict factor.

In line with the results of this study, experts (educators, child development specialists and other specialists working with children) can plan activities allowing the participation of fathers as well as activities that fathers are involved to increase the quality of the father-child relationship. In addition, they can hold activities that can make a positive and permanent impact on children such as site visits or training activities within and outside the school that fathers can join. Besides, initiatives can be proposed for family participation like article box, brochures, posters, seminars and conferences. Collaborations with parents can be developed through various family participation activities, fostering more active and permanent learning in parents and children. Furthermore, there can be arrangements to allow for the participation of fathers as well in diverse activities such as play, drama, leisure time activities, music and arts in preschool period to enhance the father-child relationship. Finally, researchers working in this area can organise training programs or educational activities for educational levels following preschool period to enhance the relationship between fathers and children. 